\title{
THE CONTRIBUTE OF GEOMATICS FOR MONITORING THE GREAT LANDSLIDE OF MAIERATO, ITALY
}

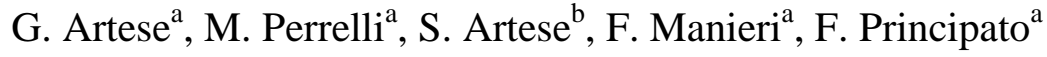 \\ ${ }^{a}$ University of Calabria - Geomatics Lab. - Civil Engineering Dept., Via P. Buccicubo 46B, 87036 Rende, Italy - \\ (g.artese, michele.perrelli)@unical.it \\ ${ }^{\mathrm{b}}$ DEIS Dept. of Electronics, Informatics and Systems, Via P. Buccicubo 41C, 87036 Rende, Italy
}

WG I/2, I/6, ICWG I/V, V/3, V/5

KEY WORDS: Landslide, Monitoring, Total Station, Control Network

\begin{abstract}
:
In the framework of the activities aimed to acquire knowledge and to monitor landslides, an important role is played by geomatics. Topographic surveying is generally used to describe the external surface, to measure the displacements of selected points and to evaluate morphological evolutions. Monitoring is generally extended to the structures located near the crown and the ridges of the landslide. In case of great landslides, a large number of activities (geological, geotechnical, etc...) is performed, and the need to coordinate all of the studies is felt. Presently, the topographic monitoring of some great landslides is in progress in Calabria, performed by the Geomatics Lab of the University of Calabria, Civil Engineering Dept.

The paper deals with the support given by geomatics for monitoring operations of a large landslide, filmed in real time. It affects an entire hill at the edge of the city of Maierato, southern Italy, whose main access road has been bisected. To understand the event, the geophysical and geotechnical methods of investigation have been integrated with geomatic methods.

The geophysical and geotechnical measurements in the area were performed by using inclinometers, seismic testing and tomography; some piezometers have been also installed. The geomatic methods used are: GNSS surveys, laser scanner, digital photogrammetry, total station (continuously operating). GNSS receivers were used in static mode for the reference points. Kinematic and RTK surveys have been performed to obtain the cross sections, useful to correctly interpret the tomography. Laser scanner has been used to obtain a 3D model of the area and to evaluate the volume of the landslide. The total station controls and transmits continuously the position of 20 points.

The design of the control network and the data acquired during the first periodare discussed, with a peculiar attention to the influence of the atmospheric parameters. The first months of monitoring show, on the one hand, an excellent repeatability of the measures, on the other, they confirm what has been obtained with other punctual techniques (inclinometers, etc...) and areal surveys. The integration of the investigations and their results will allow the development of a model of the landslide, also useful for the early warning.
\end{abstract}

\section{INTRODUCTION}

\subsection{Geomatics in Landslides monitoring activities}

For monitoring landslides, geomatics methods are widely diffused. Landslides are monitored by using total stations (Stiros et al., 2004, Tsaia et al., 2012), laser scanner both conventional (Kasperski et al., 2010, Lichun et al., 2008) and recent models capable to give full-waveform (Mallet and Bretar 2009, Pirotti et al., 2013a). GNSS receivers are used since several years (Josep et al., 2000) and recent applications use low cost instruments (Glabsch et al., 2009). SAR interferometry is used both from satellite (Kimura and Yamaguchi, 2000) and terrestrial (Tarchia et al., 2003).

All of the geomatics-related activities should be integrated with geotechnical and geophysical surveys, in order to better understand the collapse mechanism of the landslide and to set up a model, also useful for early warning.

The paper concerns the contribute given by geomatics to monitoring operations of a large landslide, made famous by filming in real time.

In the area, measurements were carried out using inclinometers, seismic testing and tomography; some piezometers have been in addition installed. The geomatics surveys which were carried out described in the paper have been performed by using total station (continuously operating) and GNSS receivers.

\section{THE LANDSLIDE OF MAIERATO}

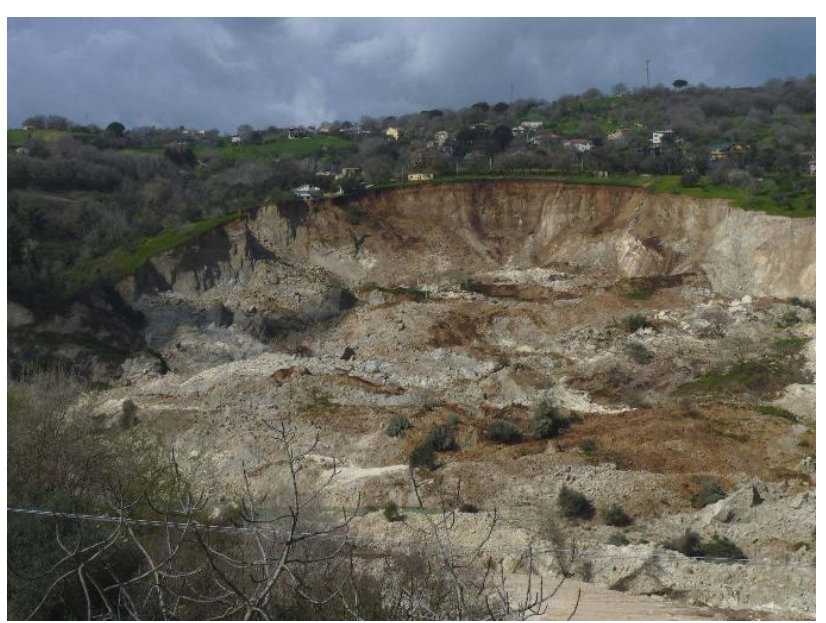

Figure 1. The crown of the Maierato Landslide

The landslide of Maierato (figure 1) occurred on February 15th 2010; it is located west of the town and its crown has a width of about $500 \mathrm{~m}$, while the whole length is of about $1400 \mathrm{~m}$. On the 
night between 20 and 21 February, another flow occurred, resulting in a withdrawal of the slope of about $80 \mathrm{~m}$ in the central part of the main crown,which caused a detachment having a width of about $200 \mathrm{~m}$ (Comerci and Di Manna, 2010).

The flow occurred in south-east direction and the volume of the material collapsed was estimated at 1-2 million cubic meters (Figure 2). This large amount of material has filled the valley of the river Scotrapiti enough to reverse, in some points, the direction of the slope and to create some small hills on the bottom of the valley (Figure 3 ). In some areas the backfilling created by the landslide has exceeded a thickness of 15-20 meters. The flow buried, in the downstream section, some old mills and dragged a house, visible in figure 4, for about 200 metres. The landslide also has formed a barrier on the Scotrapiti creek, creating some ponds in the upstream. Two days after the landslide, the lake along the ditch had a length of about $250 \mathrm{~m}$.

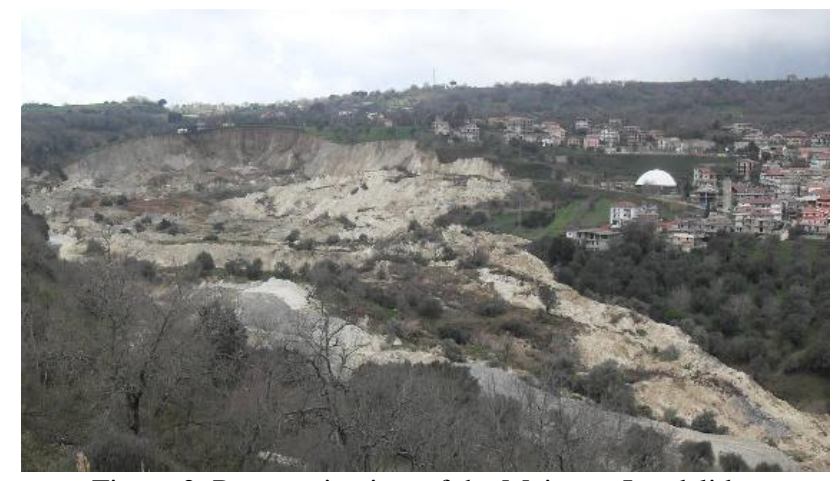

Figure 2. Panoramic view of the Maierato Landslide

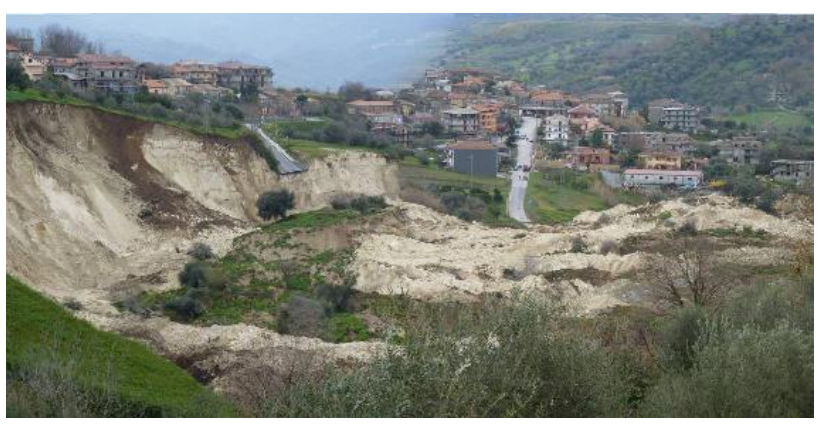

Figure 3. Soil waves on the bottom of the Scotrapiti valley

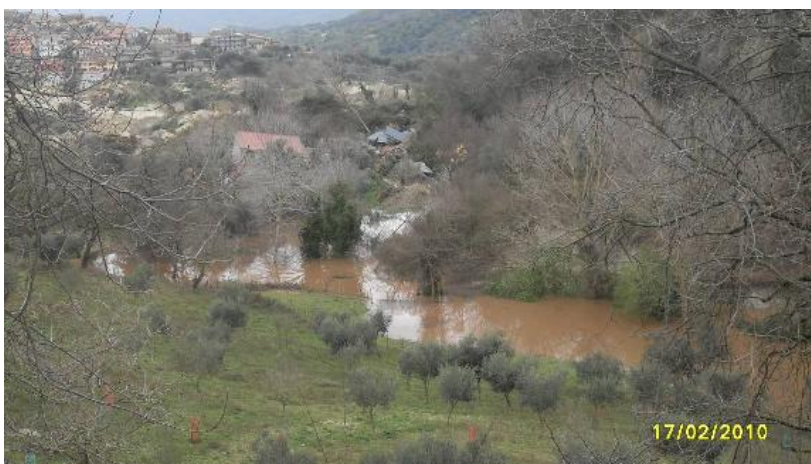

Figure 4.Water pool on the bottom of the Scotrapiti valley

\section{MONITORING ACTIVITIES}

\subsection{Geotechnical and geophysical investigations}

To determinate the depth of the sliding surface of the landslide, several drillings have been made; two holes have been equipped with inclinometers to detect deep movements and three piezometers have been realized to control the aquifer level.On the basis of these investigations and of laboratory tests, a model of the sliding surface has been carried out by Conte (Conte, 2012).

In order to improve the hydrogeological characterization of the aquifer of Maierato, high resolution geo-electric tomographies have been performed (Rizzo and Straface, 2012)

\subsection{Geomatics applications}

\subsubsection{Total Station}

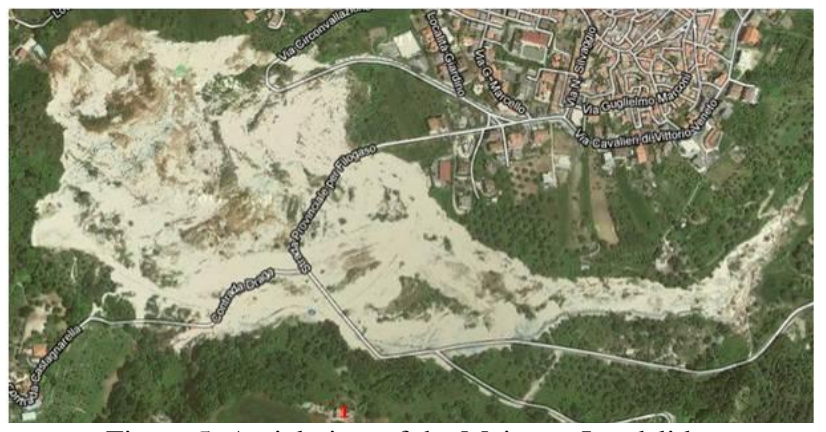

Figure 5. Aerial view of the Maierato Landslide

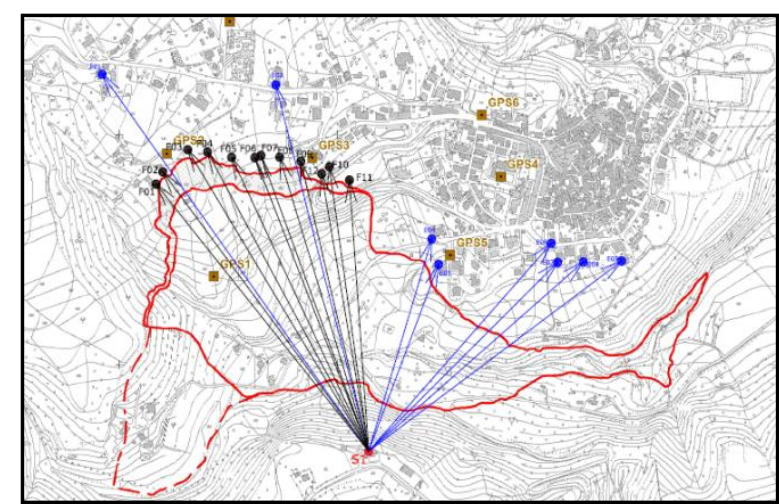

Figure 6.Total Station survey layout

The landslide of February 15th 2010 was preceded by premonitory phenomena, among which cracks and deformations in the surrounding zone and on the road; also the detachment occurred on the night between 20 and 21 February gave warning signs. According with geological and geotechnical investigations, we can expect movements of some centimeters near the crown of the landslide, whilst the buildings seem to be close, but outside the unstable zone. Thus we should be able to detect sub-centimetric movements of the points on the buildings.

Taking into account also economic availabilities, it has been chosen to install a permanent station located on a balcony of a building, sited on the opposite side of the landslide, from which it is possible to observe almost the entire crown and the town. The topographic monitoring of the landslide involves 20 points (Figure 6), 12 of which are located along the crown of the landslide (black dots) and 8 on some surrounding buildings 
(blue dots). On every point a retro-reflective prism has been installed for the execution of continuous monitoring.

To set up the permanent monitoring system, a total station Leica TS30 has been used. The total station is connected to a panel for the remote control and for data exchange. The monumentation consists of an iron bracket specially designed and equipped with a Plexiglas cover for the protection against wind and rain, which was fixed on a wall of the building (Figure 7).

The main characteristics of the station (Bayoud, 2006)are the following:

Angular accuracy

Pinpoint EDM accuracy

Carrier wave

$$
\begin{aligned}
& 0,5 ” \\
& 0.6 \mathrm{~mm}+1 \mathrm{ppm} \\
& 658 \mathrm{~nm}
\end{aligned}
$$

Automatic Target Recognition (ATR) accuracy

$$
1 "
$$
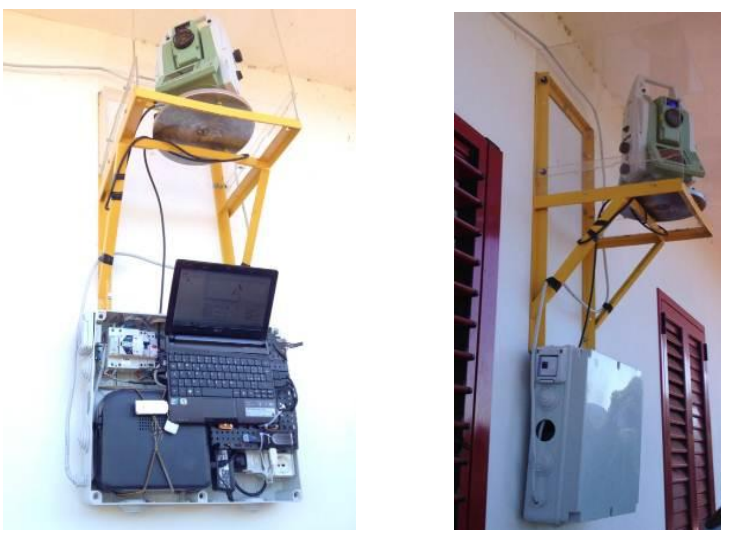

Figure 7. The total station and the control panel

The control panel houses a processing unit, a data transmission module, a device for electrical protection, a switch-box controllable remotely for the restart of the total station in case of malfunction and an uninterruptible power supply to ensure proper functioning even in a failure of electrical network powerup to 3 hours.

Along the crown of the landslide, the reflecting targets were positioned, by using iron bars grounded with concrete and braced; iron brackets were used to fix the remaining prisms to the walls of the surrounding buildings (Figure 8).

Data are collected every 20 minutes and are sent to the Geomatics Lab of the University of Calabria, where processing is performed.

The monitoring setup is adequate, with respect to the expected movements. Thanks to the top level performances of the total station and taking into account a point sited at a distance of about $700 \mathrm{~m}$, it should be possible,theoretically, to reach theprecision (at $2 \sigma$ ) of $1.7 \mathrm{~mm}$ for the height, $1 \mathrm{~mm}$ for the distance and $2 \mathrm{~mm}$ for the planimetric position.

To take full advantage of the characteristics of the total station, it is mandatory to apply an atmospheric correction; in order to limit the error of the EDM to $1 \mathrm{ppm}$, the following parameters must be acquired: air temperature to $1^{\circ} \mathrm{C}$, air pressure to 3 mbar and relative humidity to $20 \%$.

During the first months of the monitoring activities, the climatic data were not available for the landslide zone, so we used the information given by the closest meteorological station, sited in Vibo Valentia (3 $\mathrm{km}$ away and at the same altitude).

It is reasonable to foreseen a maximum difference of the daily average temperatureof about $1{ }^{\circ} \mathrm{C}$, while for air pressure and relative humidity, the values of 2 mbar and $10 \%$ could be considered.By using these values, the previously indicated precision of the measurements of distances for the points on the buildings should be almost doubled.
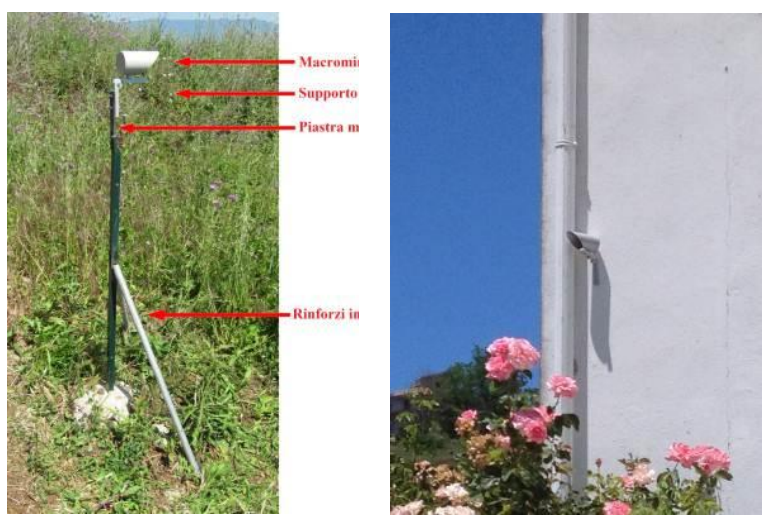

Figure 8.Targets positioned on the landslide crown (left) and on the wall of a building (right)

\subsubsection{GNSS survey}

In addition to the topographic surveying, acquisitions were performed with a Leica Viva GNSS receiver, both along the crown and in the body of the landslide. These acquisitions were performed in kinematic mode, so as to obtain several points to derive a rough numerical model of the surface. It was followed the path corresponding to the tomography sections. The acquisitions were obtained on June $4^{\text {th }} 2012$, when the pond of figure 4 was dry. For the differential processing, the data collected by the permanent station of Tropea (few kilometers away) were used.

Some views of the model obtained are shown in figure 9; the red line shows the route of the longitudinal tomography performed.
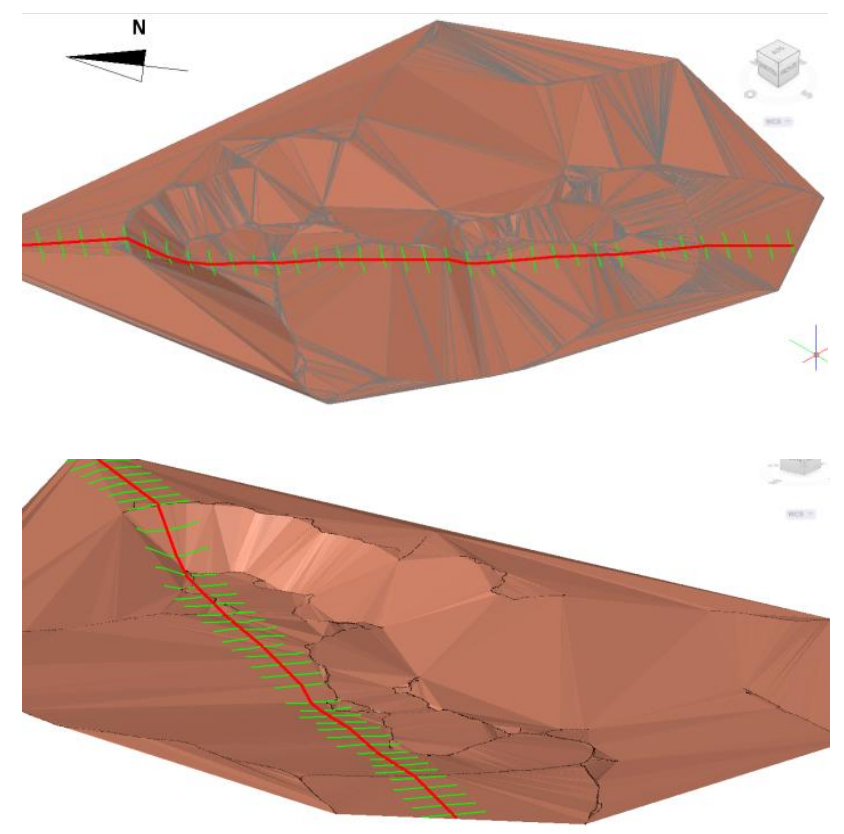

Figure 9.TIN of the landslide area

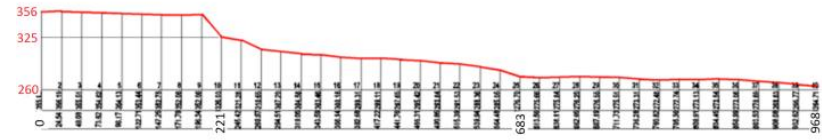

Figure 10. Cross section along the tomography path 


\section{FIRST RESULTS}

In the following, the results obtained by the total station monitoring for the first six months are presented.

It was chosen a local reference system having the origin in the centre of the total station. As reference direction it was used the point E1, monumented on a building one km away.

To correct the EDM measurements from the atmospheric effects, the following formula based on Barrel and Sears model(Barrell H. and Sears J. E., 1939) and obtained for a wavelength of $658 \mathrm{~nm}$ has been used

$\Delta \mathrm{D}_{1}=286.34-\left[\frac{0.29525 p}{(1+\alpha t)}-\frac{4.12610^{-4} h}{(1+\alpha t)} 10^{x}\right]$

where:

$\Delta \mathrm{D}_{1}=$ atmospheric correction in $\mathrm{ppm}$

$\mathrm{p}=$ atmospheric pressure in mbars

$\mathrm{h}=$ relative humidity

$\mathrm{t}=$ air temperature in ${ }^{\circ} \mathrm{C}$

$\alpha=1 / 273.15$

$x=(7.5 t /(237.3+t))+0.7857$

Thanks to our station setup, it's possible nowadays to analyze a big set of data in order to study the superficial evolution of the landslide.The first monitoring months confirm some small movements along the crown, also in the dry season, while the built zone seems to be more stable.
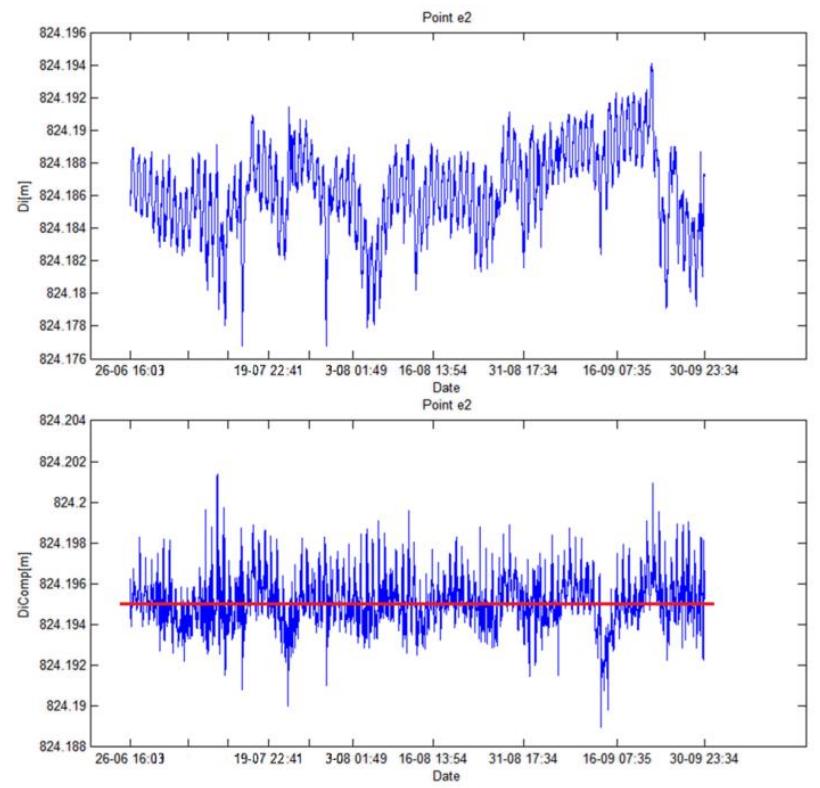

Figure 11. Raw and corrected values of distance for point e2 (on a building)

Figure 11 shows the distance from the station to a building, before and after atmospheric correction: the interpolating straight lines are horizontal, with a standard deviation of about 3 $\mathrm{mm}$ for the raw data and of $1 \mathrm{~mm}$ for the corrected ones. This value is consistent with the expected accuracy of the total station $(2 \mathrm{~mm}$ at $2 \sigma)$.
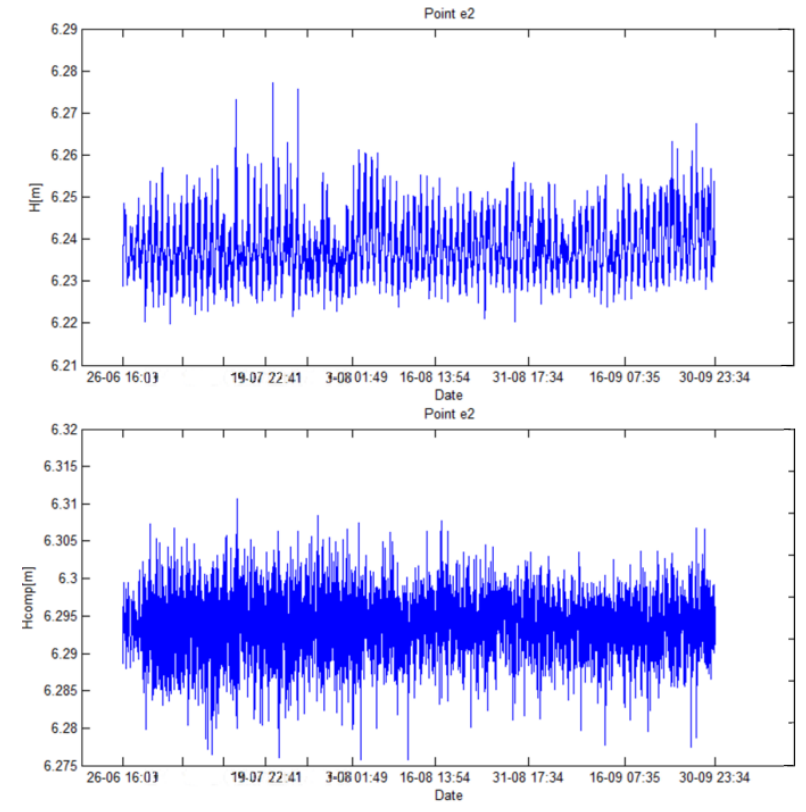

Figure 12. Raw and corrected values of height for point e2 (values are referenced to the station)
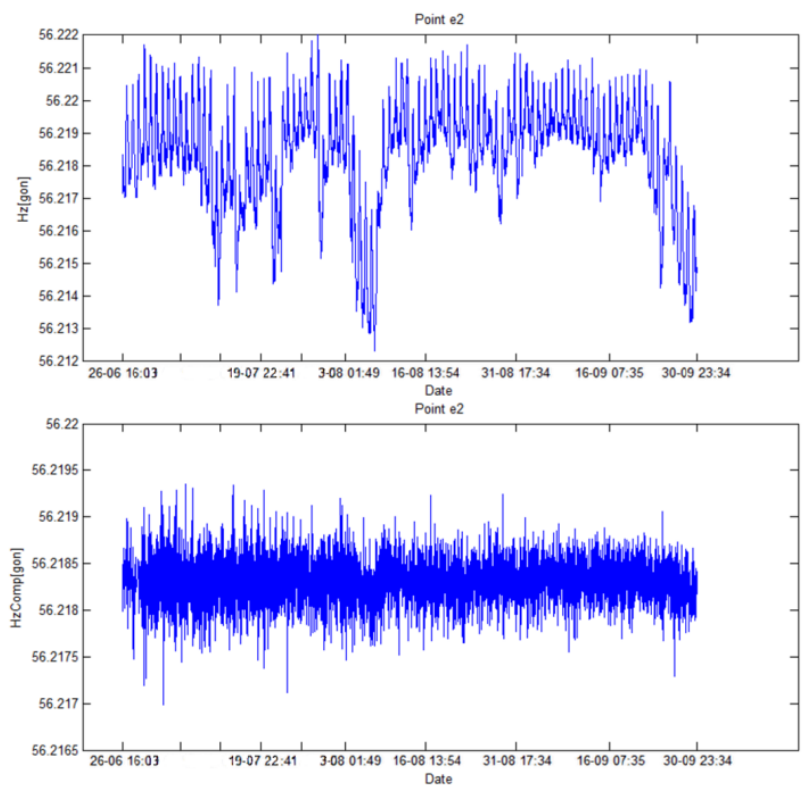

Figure 13. Raw and corrected values of horizontal angle for point e2

Similar remarks can be made about the trend of height and of horizontal angle, represented in figures 12 and 13.

In figure 14 the envelope of the planimetric positions of point e2, obtained by raw data, is shown. The envelope of the positions is elliptical in shape, with the semi-major axis orthogonal to the line joining the centroid obtained by using the acquisitions of the first week (green dot) and the station (red line) and the semi-minor axis placed along the same joining line. This shape was to be expected: actually, the errors of the Automatic Target Recognition system cause a variation of the position of the measured point greater than the one induced by the errors of the EDM.

Figure 15 shows the envelope obtained by corrected observations. Also in this case the elliptical shape is evident. 


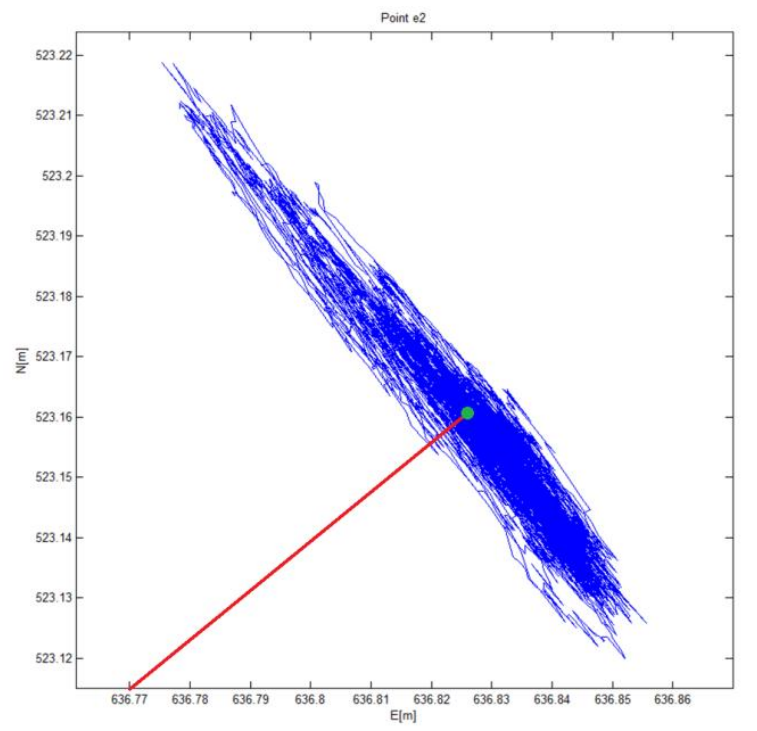

Figure 14. Envelope of the planimetric position obtained by raw data for point e2 (coordinates are referenced to the station)

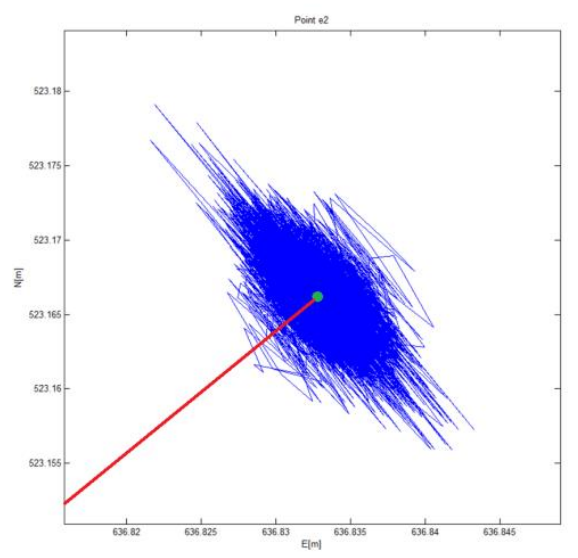

Figure 15. Envelope of the planimetric position obtained by corrected observations for point e2
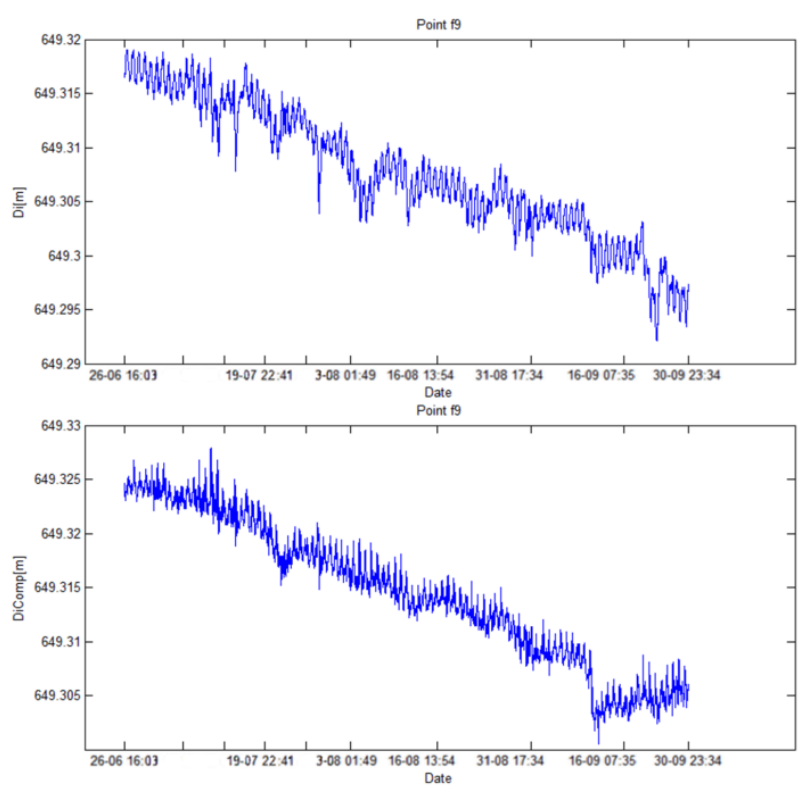

Figure 16. Raw and corrected values of distance for point f9
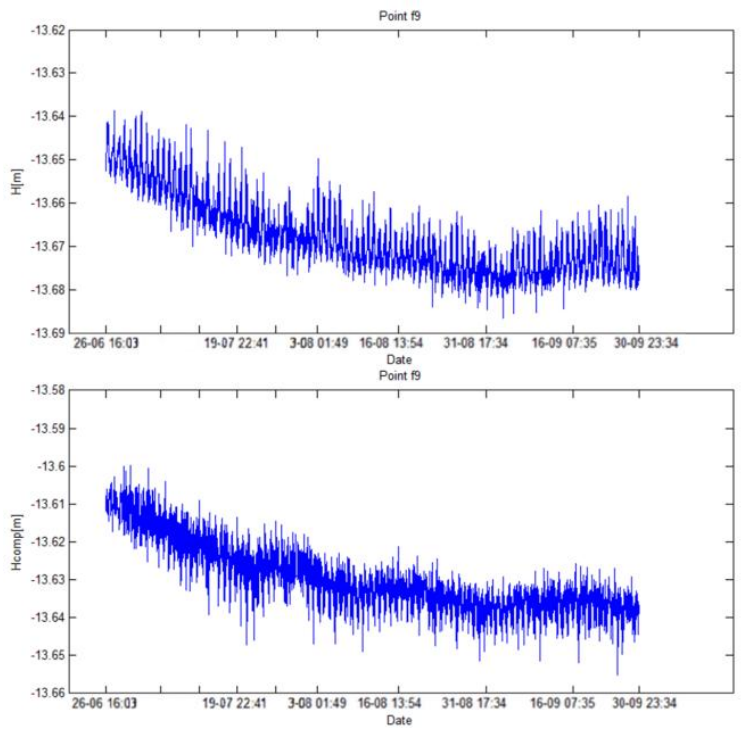

Figure 17. Raw and corrected values of height for point $\mathrm{f9}$ (with reference to the station)

Figures 16 and 17 show the values of distance and height obtained by raw and corrected observations for point $\mathrm{f} 9$, positioned near the crown of the landslide.

The envelope of the planimetric position obtained by raw and corrected observations for the same point is represented in figures 18 and 19.

We can observe anoticeablemovement of about $25 \mathrm{~mm}$ along a direction almost orthogonal to the border of the crown and alowering with the same magnitude.

Similar results have been obtained for the other points positioned near the landslide crown.

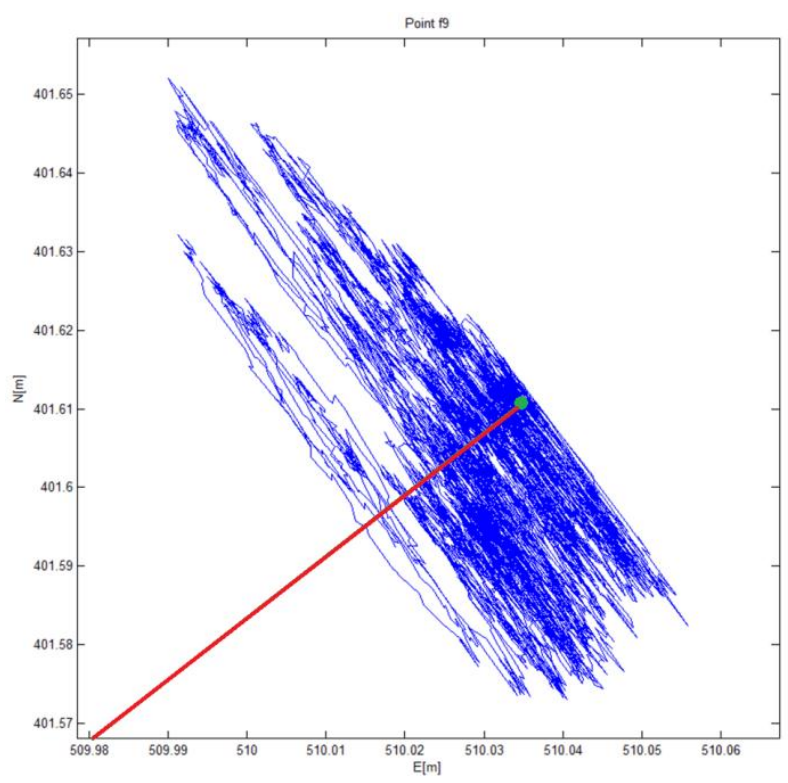

Figure 18. Envelope of the planimetric position obtained by raw observations for point $\mathrm{f} 9$. 


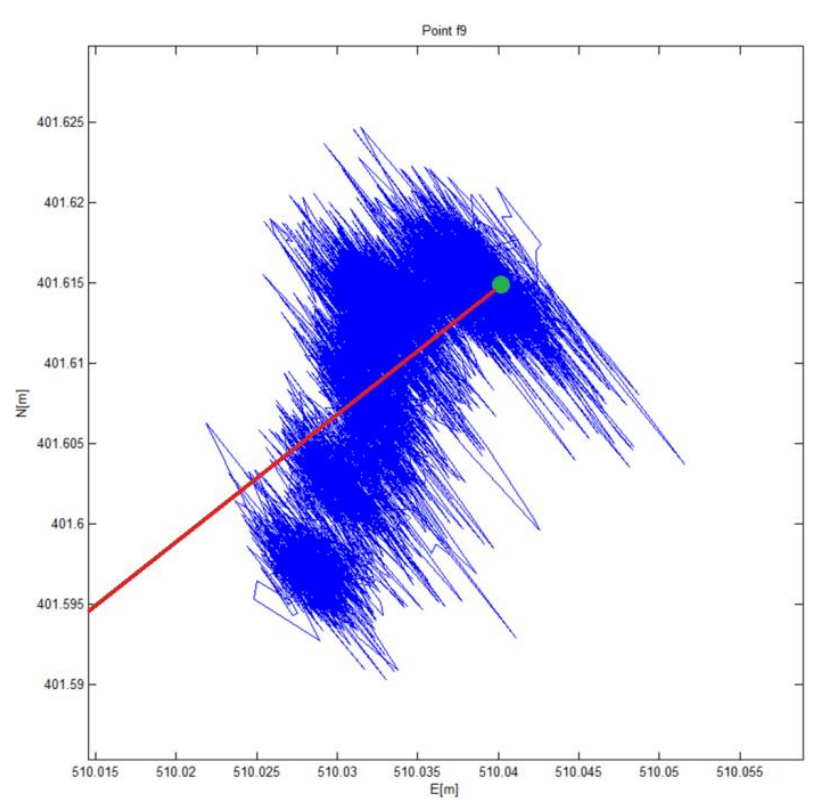

Figure 19.Envelope of the planimetric position obtained by corrected observations for point $\mathrm{f} 9$

\section{CONCLUSIONS AND FUTURE ACTIVITIES}

The activities carried out using geomatic techniques in the framework of the monitoring of a large landslidehave been described. GNSS receivers have been used and kinematic surveys have been carried out to obtain the cross sections, useful to correctly interpret the tomography. A total station operating continuously has been used. The data acquired during the first months of monitoring has been discussed, with a peculiar attention to the influence of the atmospheric parameters. The first six months of surveying show, on the one hand, an excellent repeatability of the measures, on the other, a confirmation that some points near the crown border are moving to some degree.

In the future, the activities with the total station will continue. The use of terrestrial laser scanner is foreseen, along with digital photogrammetry.

\section{BIBLIOGRAPHY}

Barrell H., Sears J. E., 1939.The Refraction and Dispersion of Air for the Visible Spectrum.Philosophical Transactions of the Royal Society of London. Series A, Mathematical and Physical Sciences Vol. 238, No. 786, London,pp. 1-64

Bayoud, F.A., 2006. Leica's Pinpoint EDM Technology with Modified Signal Processing and Novel Optomechanical Features.Proceedings XXIII FIG Congress.Munich, Germany, October 8-13, 2006

Bertacchini, E., Capra, A., Castagnetti, C., Corsini, A., 2011. Atmospheric corrections for topographic monitoring systems in landslides. FIG Working Week Bridging the Gap between Cultures. Marrakech, Morocco, 18-22 May 2011

Comerci, V., Di Manna, P., 2010. Secondo Verbale di sopralluogo sulla frana di Maierato (VV) - marzo 2010 Technical Report - ISPRA

Conte, E., 2012. Report AM/R14/A_M5/a Studi ed indagini geologiche, geotecniche, idrologiche ed idrauliche nel comune di Maierato. Agreement between CAMILAB-University of Calabria and Deputy Commissioner for the hydrogeological emergency (P.Versace coordinator).

Glabsch, J. Heunecke, O., Schuhbäck, S., 2009.Monitoring the Hornbergl landslide using a recently developed low cost GNSS sensor network.Journal of Applied Geodesy. Volume 3, Issue 3, Pages 179-192,

Josep, A. Gilia, J. A., Corominasa, J., Riusa, J., 2000. Using Global Positioning System techniques in landslide monitoring, Engineering Geology, Volume 55, Issue 3, February 2000, pp 167-192

Kasperski, J., Delacourt, C., Allemand, P., Potherat, P., Jaud, M., Varrel, E., 2010. Application of a Terrestrial Laser Scanner (TLS) to the Study of the Séchilienne Landslide (Isère, France).Remote Sensing, 2, 2785-2802

Kimura, H., and Yamaguchi Y., 2000.Detection of Landslide Areas Using Satellite Radar Interferometry.Photogrammetric Engineering \& Remote Sensing Vol.66, n. 3, March 2000, pp. 337-344.

Leica TS30/TM30 Manual 1.1- 2009

Lichun, S., Wang, X., Zhao d.,Qu j., 2008. Application of 3D laser scanner for monitoring of landslide hazards.The International Archives of the Photogrammetry, Remote Sensing and Spatial Information Sciences.Vol. XXXVII Part B1, Beijing, pp. 277-281

Mallet, C., Bretar, F.,2009. Full-waveform topographic Lidar: State-of-the-art. ISPRS Journal of Photogrammetry and Remote Sensing, 64, pp 1-16.

Pirotti, F., Guarnieri A.,Vettore A., 2013a. Ground filtering and vegetation mapping using multi-return terrestrial laser scanning. ISPRS Journal of Photogrammetry and Remote Sensing, 76, pp 56-63.

Pirotti, F., Guarnieri, A., Vettore, A. 2013b. State of the art of ground and aerial laser scanning technologies for highresolution topography of the earth surface. European Journal of Remote Sensing, 46, pp 66-78.

Rizzo, E., Straface, S.,2012. Report AM/R16/A_M10/a, Studi ed indagini geologiche, geotecniche, idrologiche ed idrauliche nel Comune di Maierato.Agreement between CAMILABUniversity of Calabria and Deputy Commissioner for the hydrogeological emergency (P.Versace coordinator).

Stiros, S.C., Vichas, C., Skourtis, C., 2004. Landslide MonitoringBased On Geodetically Derived Distance Changes, J. Surv. Eng.-ASCE, 130(4), 156-162, 2004.

Tarchia, D., Casagli, N., Fanti, R., Leva, D., Luzic, G., Pasuto, A., Pieraccini, M., Silvano, S., 2003. Landslide monitoring by using ground-based SAR interferometry: an example of application to the Tessina landslide in Italy.Engineering Geology, Volume 68, Issues 1-2, February 2003, Pages 15-30

Tsai, Z., You, G.J.Y., Lee, H.Y., Chiu, Y.J., 2012. Use of a total station to monitor post-failure sediment yields in landslide sites of the Shihmen reservoir watershed. Geomorphology 139-140, Taiwan, pp. 438-451. 